\title{
Effect of 10\% Sodium Ascorbate on Bleached Bovine Enamel Surface Morphology and Microhardness
}

\author{
Parnian Alizadeh Oskoee ${ }^{1}$, Elmira Jafari Navimipour ${ }^{1, *}$, Siavash Savadi Oskoee $^{1}$ and Najmeh \\ Moosavi $^{2}$ \\ ${ }^{I}$ Department of Operative Dentistry, Faculty of Dentistry, Tabriz University of Medical Sciences, Tabriz, Iran \\ ${ }^{2}$ Department of Prosthodontics, Faculty of Dentistry, Ahvaz University of Medical Sciences, Ahvaz, Iran
}

\begin{abstract}
Sodium ascorbate has recently been suggested to compensate decreased bond strength of composite resin to bleached tooth surfaces. The aim of present study was to evaluate the effect of $10 \%$ sodium ascorbate on bleached bovine enamel morphology and microhardness considering the possibility of its effect on enamel surface characteristics. A total of 69 bovine enamel slabs were prepared and mounted in acrylic resin. Subsequent to polishing, they were randomly divided into 3 groups of 23 specimens each; 3 for Scanning Electron Microscopy (SEM) analysis and 20 for hardness test. In group 1 the specimens were immersed in distilled water as control group; in group 2 the specimens were bleached with $35 \%$ carbamide peroxide for 30 min a week for 3 consecutive weeks; and in group 3 the specimens were exposed to $10 \%$ sodium ascorbate for $30 \mathrm{~min}$ subsequent to bleaching similar to group 1. After 3 weeks Vickers hardness of the specimens was measured at 3 points with equal distances from each other under a force of $50 \mathrm{~g}$. The mean of the hardness values of each specimen was calculated and data was analyzed by one-way ANOVA $(\mathrm{P}<0.05)$. The highest and lowest microhardness values were observed in group 1 and group 2, respectively. However, there were no statistically significant differences in microhardness between the groups $(\mathrm{P}=0.12)$. The use of $35 \%$ carbamide peroxide alone or with $10 \%$ sodium ascorbate does not affect bovine enamel hardness. SEM analysis showed a network of sodium ascorbate adsorbed to the bleached enamel surface.
\end{abstract}

Keywords: Enamel, Sodium Ascorbate, Carbamide Peroxide, Microhardness, Morphology.

\section{INTRODUCTION}

With an increase in the demand for esthetics, vital bleaching has become a popular conservative treatment modality for discolored teeth, and bleaching agents with varying concentrations have been introduced to achieve rapid esthetic results [1]. Vital bleaching technique is divided into in-office and at-home procedures carried out by the dental practitioner and the patient, respectively [2]. High concentrations of oxidizing agents such as $35-37 \%$ carbamide peroxide and 30$35 \%$ hydrogen peroxide for use in the office [3], and low concentrations such as 3-7\% hydrogen peroxide and $10-20 \%$ carbamide peroxide for use at home by the patient are available [4], with advantages and disadvantages for each agent. Some of the advantages of the in-office technique are that everything is under the control of the practitioner, soft tissues are properly protected, and the procedure will yield good results in a short period of time [5]. Despite the effect of above-mentioned factors on tooth bleaching, complications such as pulp irritation, tooth structure alterations, microleakage of restorations, and reduced bond strength of composite resin to tooth structure might arise. Some studies have reported changes in enamel, including increased porosity and an over-etched appearance along with loss of prismatic enamel structure, calcium loss, reduced microhardness, and changes in the organic component of enamel $[6,7]$.

*Address correspondence to this author at the Department of Operative
Dentistry, Tabriz School of Dentistry, Golgasht Street, Daneshgah Avenue,
Tabriz, Post Code: 5166614713, Iran; Tel: 0098 4113355965-6; Fax: 0098
4113346977; E-mail: elmiranavimi@yahoo.com or elm-jafari@tbzmed.ac.ir
One of the most important complications of the use of bleaching agents is decreased composite resin bond strength to enamel immediately after bleaching procedure $[6,8]$. Some studies have attributed this decreased bond strength to the presence of oxygen ions [9-11]. Therefore, some techniques have been proposed to modify the clinical complications related to decreased bond strength subsequent to bleaching. The most common technique is a delay of one to three weeks after the bleaching process $[6,8]$. Some other studies have demonstrated that reduced bond strength can be reversed by the use of antioxidants such as sodium ascorbate $[6,8,10,11]$. Therefore, restorative procedures are possible immediately after bleaching, which shortens the overall time needed for esthetic procedures.

On the other hand, some studies have attributed the decreased bond strength to the softening of tooth structure subsequent to bleaching [12-14]. Sodium ascorbate is a derivative of ascorbic acid with a neutral $\mathrm{pH}$. The use of ascorbic acid as an antioxidant has not been recommended after bleaching because of its acidity [8]. Besides SEM images have demonstrated an etched appearance on enamel surfaces after ascorbic acid use in bleached enamel specimens [9].

The aim of the present study was to evaluate the effect of $10 \%$ sodium ascorbate on surface characteristics of bleached enamel, including surface morphology and microhardness.

\section{MATERIALS AND METHODS}

In this in vitro study sixty nine sound bovine incisors were collected and immersed in $2 \%$ chloramine $\mathrm{T}$ solution 
Table 1. Microhardness Values (Mean \pm SD) of the Study Groups

\begin{tabular}{|c|c|c|c|c|c|}
\hline Maximum & Minimum & SD & Mean & n & Group \\
\hline \hline 379.61 & 350.97 & 30.59 & 365.29 & 20 & 1. Control \\
\hline 359.57 & 336.36 & 24.26 & 347.72 & 20 & 2. C.P. \\
\hline 366.73 & 342.22 & 26.19 & 354.48 & 20 & 3. C.P.+ S.A. \\
\hline
\end{tabular}

C.P. (Carbamide Peroxide), S.A. (Sodium Ascorbate) $\mathrm{n}$ (number), SD (standard deviation)

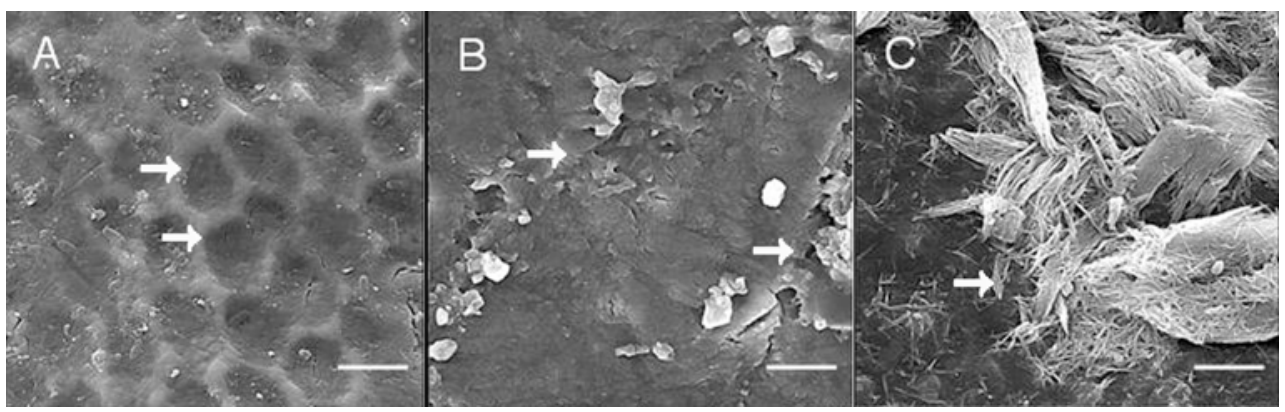

Fig. (1). SEM images $(\times 5000)$ of bovine enamel in the study groups; (A) Unbleached enamel: enamel rods with keyhole appearance can be seen in transverse section. (B) Enamel bleached with 35\% carbamide peroxide: the enamel rods have lost their integrity. (C) Enamel treated with $10 \%$ sodium ascorbate subsequent to bleaching with $35 \%$ carbamide peroxide: a network of sodium ascorbate adsorbed to the bleached enamel surface can be seen. (bar: $5 \mu \mathrm{m}$ ).

for disinfection at $4{ }^{\circ} \mathrm{C}$ immediately after extraction. All the tooth surfaces were examined for any softness, scratches, or any other defects using a dental explorer and under a stereomicroscope (Nikon SMZ 1000; Tokyo, Japan). Then the crowns of the teeth were separated at CEJ (cemento-enamel junction) using a diamond disk. Sixty enamel slabs measuring $3 \times 3 \times 2 \mathrm{~mm}$ were prepared from the crowns of the teeth using a two-sided diamond disk (Brasseler Savannah, USA) under water spray. Then the enamel specimens were mounted in self-curing acrylic resin and polished using Soflex disks (3M ESPE, MN, USA) under water spray to produce flat surfaces for microhardness measurement procedure. The specimens were then randomly divided into 3 groups of 23 specimens each.

In group 1 (control group), the specimens were kept in distilled water at $37{ }^{\circ} \mathrm{C}$ for three weeks. The distilled water was changed everyday.

In group 2, the surface of enamel specimens was exposed to a predetermined volume $(0.01 \mathrm{~mL})$ of the bleaching agent containing 35\% carbamide peroxide (Opalescence Quick; Ultradent, South Jordan, USA) for 30 min a week for 3 consecutive weeks. During the intervening period after rinsing the bleaching agent under running water for one minute, the specimens were kept in distilled water at $37^{\circ} \mathrm{C}$.

In group 3, subsequent to the application of $35 \%$ carbamide peroxide similar to group 2, the surface of the enamel specimens was exposed to $10 \%$ sodium ascorbate for $30 \mathrm{~min}$. During this exposure the solution on the enamel surface was agitated every $10 \mathrm{~min}$ using a sterile brush. After the application of sodium ascorbate, the enamel surfaces were thoroughly rinsed under running water for $30 \mathrm{~s}$ and then kept in distilled water at $37^{\circ} \mathrm{C}$.
Prior to microhardness measurement, three specimens were randomly selected from each group for surface morphology evaluation under a Scanning Electron Microscope (TESCAN VEGA; USA) at magnification $\times 5000$. Then Vickers hardness was measured for the remained specimens of the groups using Shimadzu hmv-2000 (Shimadzu, Tokyo, Japan) at room temperature under $50 \mathrm{~g}$ force for $15 \mathrm{~s}$. Three measurements were made with three indentations at equal distances from each other on the flat surface of each specimen. Microhardness means were calculated for each specimen and data was analyzed using one-way ANOVA at a significance level of $\mathrm{P}<0.05$.

\section{RESULTS}

The results of Vickers hardness measurements in the study groups are presented in Table $\mathbf{1}$. The highest and lowest microhardness values were recorded in groups 1 and 2; respectively.

One-way ANOVA analysis did not demonstrate any significant differences in the means of microhardness values between the three groups $(P=0.12)$. SEM images showed that $35 \%$ carbamide peroxide had made surface topographic changes compared to normal enamel surface (Fig. 1A and 1B). In addition, a complex network was observed on the bleached enamel subsequent to the use of $10 \%$ sodium ascorbate (Fig. 1C).

\section{DISCUSSION}

Enamel surface microhardness measurements are used to evaluate changes related to the mineral content of enamel. This method has been repeatedly used to evaluate the effect of bleaching agents on tooth structure and restorative materials [12-16]. Regarding the scarcity of human enamel and similarities between human and bovine enamel [17], bovine 
enamel was used as an alternative to human enamel in the present study to evaluate the effect of $35 \%$ carbamide peroxide alone and in conjunction with $10 \%$ sodium ascorbate on enamel microhardness. The results of this study indicated that $35 \%$ carbamide peroxide reduces enamel surface microhardness, however the differences were not statistically significant. Some studies have not reported any changes in enamel surface microhardness subsequent to the use of bleaching agents [15,18-22]. In a study carried out by Rodrigues et al. the concomitant use of in-office and at-home bleaching agents did not result in any changes in enamel surface microhardness [23]; however, Lee et al. demonstrated decreases in enamel surface microhardness subsequent to the use of in-office bleaching agents [24]. Lewinstein et al. [25] and Ferreira et al. [26] reported a marked decrease in enamel surface microhardness subsequent to the use of in-office bleaching agents. Soldani et al. reported a reduction in microhardness of enamel after bleaching, clinically [27].

The effect of bleaching agent is directly related to exposure time and concentration of the active ingredient; with an increase in exposure time and concentration of bleaching agent the oxidation process will be stronger and as a result, the effect and complications will be greater [28,29]. The most common complication is weakening of enamel structure due to oxidation of organic and inorganic components and dissolution of enamel matrix [16,24,30-32], leading to loss of enamel mineral content [23,33]. McGuckin et al. demonstrated the deposition of a non-specific layer on bleached enamel surfaces using electron microscopy [31]. Zalkind et al. demonstrated that the majority of bleaching agents can produce morphologic changes on enamel surface [2]. Results of another study revealed that bleaching with carbamide peroxide over short periods of time caused nanomorphological alterations of the enamel surface, whereas prolonged exposure resulted in micromorphological changes [34]. In the present study no significant changes were observed in enamel surface microhardness despite topographic changes and loss of the typical prismatic appearance of enamel. Enamel rods in unbleached enamel can be seen with keyhole appearance in transverse section (Fig. 1A). Each rod is composed of a rounded head (body) section and a tail section [35]. Crater-like appearance in this figure may be due to $\mathrm{pH}$ of distilled water that was used as storage media [36]. In enamel specimens bleached with 35\% carbamide peroxide, the enamel rods have lost their integrity and an erosion-like pattern with increased porosities can be seen (Fig. 1B). In a study by Cavalli et al., similar structural changes in enamel has been reported [3]. Since the influence of time is greater in higher concentrations of bleaching agents $[7,37]$, it seems that short period of the contact of the bleaching agent with enamel in the present study (30 minutes a week) is probably the main factor in lack of changes in bleached enamel microhardness. In a similar study Shannon did not report any changes in surface microhardness despite topographic changes [38]. It is conceivable that the Vickers diamond penetrates into deep enamel layers, which were not affected by the bleaching agent [39]. This might have caused the similar results in the different groups in our study.
Despite an increase in surface microhardness, in the present study no statistically significant differences were observed when $10 \%$ sodium ascorbate was used subsequent to bleaching the specimens with $35 \%$ carbamide peroxide. Sodium ascorbate has drawn a lot of attention in dentistry because of its reducing capacity and its ability to increase the strength of the adhesive bond to bleached enamel [40,41]. Sodium ascorbate is oxidized to dehydroxyascorbate in two phases after contacting with surface nascent oxygen molecules. Electrochemical studies and topographical techniques have revealed that sodium ascorbate is adsorbed to flat polymer surfaces and hydroxyapatite crystals $[42,43]$, which is consistent with SEM images of the present study (Fig. 1C). The observed effect in the present work should be attributed to the potential and strong fouling effect of dehydroascorbate, formed by contacting of ascorbic acid with carbamide peroxide [44]. It is possible that minor increase in surface microhardness subsequent the use of $10 \%$ sodium ascorbate is related to enamel surface adsorption of this agent. Although the results of the present study did not demonstrate detrimental effects of $35 \%$ carbamide peroxide or marked compensatory effects of $10 \%$ sodium ascorbate, it should be pointed out that extending the results of the present study to other bleaching systems is difficult due to the diversity of the products available and variations in their chemical composition. It is suggested that the effect of various bleaching agents with different concentrations and chemical compositions along with various concentrations of the solution and gel forms of sodium ascorbate on enamel microhardness be evaluated in order to reach a definitive conclusion. It is also suggested that other surface characteristics of bleached enamel, including surface roughness, $\mathrm{Ca} / \mathrm{P}$ ratio, the longevity of the results subsequent to bleaching, and re-staining of the teeth be evaluated in the long term following the use of sodium ascorbate.

\section{CONCLUSIONS}

Considering the limitations of the present study it can be concluded that the use of $35 \%$ carbamide peroxide alone or in conjunction with $10 \%$ sodium ascorbate does not have any detrimental effect on bovine enamel microhardness. Regarding the surface topography, SEM analysis showed a network of sodium ascorbate adsorbed to the bleached bovine enamel surface and a lost integrity of enamel rods due to bleaching process.

\section{ACKNOWLEDGEMENTS}

This project was carried out by the financial support from the Deputy Dean of Research at Tabriz University of Medical Sciences, and the cooperation of the faculty staff, to whom we extend our gratitude. We also thank Dr Majid Abdolrahimi who edited the English manuscript of this article. The authors do not have any financial interest in the companies whose materials are included in this article.

\section{REFERENCES}

[1] de Freitas PM, Turssi CP, Hara AT, Serra MC. Monitoring of demineralized dentin microhardness throughout and after bleaching. Am J Dent 2004; 17: 342-6.

[2] Zalkind M, Arwaz JR, Goldman A, Rotstein I. Surface morphology changes in human enamel, dentin and cementum following bleaching: a scanning electron microscopy study. Endod Dent Traumatol 1996; 12: 82-8. 
[3] Cavalli V, Arrais CA, Giannini M, Ambrosano GM. Highconcentrated carbamide peroxide bleaching agent effects on enamel surface. J Oral Rehabil 2004; 31: 155-9.

[4] Wattanapayungkul P, Yap AU. Effects of in-office bleaching products on surface finish of tooth-colored restorations. Oper Dent 2003; 28: 15-9.

[5] Yap AU, Wattanapayungkul P. Effects of in-office tooth whiteners on hardness of tooth-colored restoratives. Oper Dent 2002; 27: 13741.

[6] Turkun M, Kaya AD. Effect of $10 \%$ sodium ascorbate on the shear bond strength of composite resin to bleached bovine enamel. J Oral Rehabil 2004; 31: 1184-91.

[7] Attin T, Vollmer D, Wiegand A, Attin R, Betke H. Subsurface microhardness of enamel and dentin after different external bleaching procedures. Am J Dent 2005; 18: 8-12.

[8] Torres CRG, Koga AF, Borges AB. The effects of anti-oxidant agents as neutralizers of bleaching agents on enamel bond strength. Braz J Oral Sci 2006; 5: 971-6.

[9] Muraguchi K, Shigenobu S, Suzuki S, Tanaka T. Improvement of bonding to bleached bovine tooth surfaces by ascorbic acid treatment. Dent Mater J 2007; 26: 875-81.

[10] Lai SC, Mak YF, Cheung GS, et al. Reversal of compromised bonding to oxidized etched dentin. J Dent Res 2001; 80: 1919-24.

[11] Lai SC, Tay FR, Cheung GS, et al. Reversal of compromised bonding in bleached enamel. J Dent Res 2002; 81: 477-81.

[12] Rodrigues JA, Marchi GM, Ambrosano GM, Heymann HO, Pimenta LA. Microhardness evaluation of in situ vital bleaching on human dental enamel using a novel study design. Dent Mater 2005; 21: 1059-67.

[13] Leonard RH, Teixeira EC, Garland GE, Ritter AV. Effect on enamel microhardness of two consumer-available bleaching solutions when compared with a dentist-prescribed, home applied bleaching solution and a control. J Esthet Restor Dent 2005; 17: 343-50.

[14] Featherstone JD, ten Cate JM, Shariati M, Arends J. Comparison of artificial caries-like lesions by quantitative microradiography and microhardeness profiles. Caries Res 1983; 17: 385-91.

[15] Murchison DF, Charlton DG, Moore BK. Carbamide peroxide bleaching: effects on enamels surface hardness and bonding. Oper Dent 1992; 17: 181-5.

[16] Seghi RR, Denry I. Effects of external bleaching on indentation and abrasion characteristics of human enamel in vitro. J Dent Res 1992; 71: 1340-4.

[17] Sanches RP, Otani C, Damiao AJ, Miyakawa W. AFM characterization of bovine enamel and dentine after acid-etching. Micron 2009; 40: 502-6.

[18] de Oliveira R, Basting RT, Rodrigues JA, Rodrigues AL jr, Serra MC. Effects of a carbamide peroxide agent and desensitizing dentifrices on enamel microhardness. Am J Dent 2003; 16: 42-6.

[19] Haywood VB, Leech T, Heymann HO, Crumpler D, Bruggers K. Nightguard vital bleaching: effects on enamel surface texture and diffusion. Quintessence Int 1990; 21: 801-4.

[20] Gultz J, Kaim J, Scherer W, Gupta H. Two in-office bleaching systems: a scanning electron microscope study. Compend Contin Educ Dent 1999; 20: 965-8.

[21] White DJ, Kozak KM, Zoladz JR, Duschner H, Gotz H. Peroxide interactions with hard tissues: effects on surface hardness and surface/subsurface ultrastructural properties. Compend Contin Educ Dent 2002, 23: 42-8

[22] Polydorou O, Hellwig E, Hahn P. The efficacy of three different inoffice bleaching systems and their effect on enamel microhardness. Oper Dent 2008; 33: 579-86.

[23] Rodrigues JA, Erhardt MCG, Marchi GM, Pimenta LAF, Ambrosano GMB. Association effect of in-office and nightguard vital bleaching on dental enamel microhardness. Braz J Oral Sci 2003; 2: $365-9$
[24] Lee CQ, Cobb CM, Zargartalebi F, Hu N. Effect of bleaching on microhardness, morphology, and color of enamel. Gen Dent 1995; 43: $158-60$.

[25] Lewinstein I, Hirschfeld Z, Stabholz A, Rotstein I. Effect of hydrogen peroxide and sodium perborate on the microhardness of human enamel and dentin. J Endod 1994; 20: 61-3.

[26] Ferreira I, Lopes GC, Araujo E, Vieira LCC, Baratieri LN. Effect of hydrogen peroxide based home bleaching agents on enamel hardness. Braz J Oral Sci 2006; 5: 1090-3.

[27] Soldani P, Amaral CM, Rodrigues JA. Microleakage evaluation of in situ vital bleaching and thicknening agents on human dental enamel. Int J Periodontics Restorative Dent 2010; 30: 203-11.

[28] Broome JC. At-home use of 35\% carbamide peroxide bleaching gel: a case report. Compend Contin Educ Dent 1998; 19: 824-9.

[29] Leonard RH, Sharma A, Haywood VB. Use of different concentrations of carbamide peroxide for bleaching teeth: an in vitro study. Quintessence Int 1998; 29: 503-7.

[30] Bitter NC. A scanning electron microscopy study of the effect of bleaching agents on enamel: a preliminary report. J Prosthet Dent 1992; 67: 852-5.

[31] McGuckin RS, Babin JF, Meyer BJ. Alterations in human enamel surface morphology following vital bleaching. J Prosthet Dent 1992; 68: 754-60.

[32] Potocnik I, Kosec L, Gaspersic D. Effect of 10\% carbamide peroxide bleaching gel on enamel microhardness, microstructure, and mineral content. J Endod 2000; 26: 203-6.

[33] Berger SB, Cavalli V, Ambrosano GM, Giannini M. Changes in surface morphology and mineralization level of human enamel following in-office bleaching with $35 \%$ hydrogen peroxide and light irradiation. Gen Dent 2010; 58: e74-9.

[34] Fu B, Hoth-Hannig W, Hannig M. Effects of dental bleaching on micro- and nano-morphological alterations of the enamel surface. Am J Dent 2007; 20: 35-40.

[35] Sturdevant JR. In: Roberson TM, Heymann HO, Swift Jr EJ, Eds. Sturdevant's Art and Science of Operative Dentistry. St. Louis, Mosby Inc. 2006; 15-64.

[36] Anjum A, Otsuki M, Matin K, Tagami J. Preservation in the liquid media produces alterations in enamel surface properties. J Dent 2009; 37: 884-90.

[37] Grobler SR, Majeed A, Moola MH. Effect of various toothwhitening products on enamel microhardness. SADJ 2009; 64: 474-9.

[38] Shannon H, Spencer P, Gross K, Tira D. Characterization of enamel exposed to $10 \%$ carbamide peroxide bleaching agents. Quintessence Int 1993; 24: 39-44

[39] Attin T, Kielbassa AM, Schwanenberg M, Hellwig E. Effect of fluoride treatment on remineralization of bleached enamel. J Oral Rehabil 1997; 24: 282-6.

[40] Kaya AD, Türkün M. Reversal of dentin bonding to bleached teeth Oper Dent 2003; 28: 825-9.

[41] Comlekoglu ME, Gokce B, Kaya AD, Turkun M, Ozpinar B. Reversal of reduced bond strength after bleaching. Gen Dent 2010; 58: 258-63.

[42] Pournaghi-Azar MH, Ojani R. Catalytic oxidation of ascorbic acid by some ferrocene derivative mediators at the glassy carbon electrode. Application to the voltammetric resolution of ascorbic acid and dopamine in the same sample. Talanta 1995; 42: 1839-48.

[43] Akkermans RP, Ming W, Bain CD, Fidel-Suárez M, Compton RG Electroanalysis of ascorbic acid: a comparative study of laser ablation voltammetry and sonovoltammetry. Electroanalysis1998; 10: 613-20.

[44] Pournaghi-Azar MH, Dastangoo H, Fadakar R. Differentiation of detection of ascorbic acid and dehydroascorbic acid using hydrodynamic amperometry and anodic stripping voltammetry on modified aluminum electrodes. Electroanalysis 2010; 22: 229-35. 